\title{
Neuropsychology of the Prodrome to Psychosis in the NAPLS Consortium: Relationship to Family History and Conversion to Psychosis
}

Larry J. Seidman, $\mathrm{PhD}^{1}$, Anthony J. Giuliano, $\mathrm{PhD}^{1}$, Eric C. Meyer, $\mathrm{PhD}^{2}$, Jean Addington, $\mathrm{PhD}^{3}$, Kristin S. Cadenhead, $\mathbf{M D}^{4}$, Tyrone D. Cannon, $\mathrm{PhD}^{5}$, Thomas H. McGlashan, $\mathbf{M D}^{6}$, Diana O. Perkins, $\mathrm{MD}^{7}$, Ming T. Tsuang, MD, $\mathrm{PhD}^{1,4}$, Elaine F. Walker, $\mathrm{PhD}^{8}$, Scott W. Woods, MD ${ }^{6}$, Carrie E. Bearden, PhD $^{5}$, Bruce K. Christensen, PhD $^{9}$, Keith Hawkins, PsyD 6 , Robert Heaton, $\mathbf{P h D}^{4}$, Richard S. E. Keefe, $\mathbf{P h D}^{10}$, Robert Heinssen, $\mathbf{P h D}^{11}$, and Barbara A. Cornblatt, $\mathrm{PhD}^{12}$ on behalf of the NAPLS group

${ }^{1}$ Department of Psychiatry, Harvard Medical School at Beth Israel Deaconess Medical Center and Massachusetts General Hospital, Boston MA ${ }^{2}$ Department of Psychiatry and Behavioral Science, Texas A\&M Health Science Center, College of Medicine, Waco TX ${ }^{3}$ Department of Psychiatry, University of Calgary, Calgary, Alberta, Canada ${ }^{4}$ Department of Psychiatry, UCSD, San Diego CA ${ }^{5}$ Departments of Psychology and Psychiatry and Biobehavioral Sciences, UCLA, Los Angeles CA ${ }^{6}$ Department of Psychiatry, Yale University, New Haven CT ${ }^{7}$ Department of Psychiatry, University of North Carolina, Chapel Hill NC ${ }^{8}$ Departments of Psychology and Psychiatry, Emory University, Atlanta GA ${ }^{9}$ Department of Psychiatry and Behavioural Neuroscience, McMaster University, Hamilton, Ontario, Canada ${ }^{10}$ Department of Psychiatry \& Behavioral Sciences and Psychology, Duke University, Chapel Hill NC ${ }^{11}$ Schizophrenia Spectrum Research Program, Division of Adult Translational Research, National Institute of Mental Health, Bethesda MD ${ }^{12}$ Department of Psychiatry, Zucker Hillside Hospital, Long Island NY

\section{Abstract}

Context-Early detection and prospective evaluation of clinical high-risk (CHR) individuals who may develop schizophrenia or other psychotic disorders is critical for predicting psychosis onset and for testing preventive interventions.

Objective-To elucidate the neuropsychology of the CHR syndrome, to determine the association of neuropsychological function with conversion to psychosis and family history (FH) of psychosis, and to examine whether baseline neuropsychological functioning predicts subsequent psychosis.

Design, Setting, and Participants-Longitudinal study with $21 / 2$ years follow-up of 304 prospectively identified CHR individuals meeting Structured Interview for Prodromal Syndromes (SIPS) criteria, 52 non-CHR persons with a FH of psychosis in first- or second-degree relatives ("family HR"/FHR), and 193 normal controls with neither a FH of psychosis nor a CHR syndrome, all of whom had baseline neuropsychological evaluations, recruited across eight centers as part of the North American Prodrome Longitudinal Study (NAPLS).

Corresponding Author: Larry J. Seidman, PhD, Department of Psychiatry, Massachusetts Mental Health Center Public Psychiatry Division of the Beth Israel Deaconess Medical Center, 401 Park Drive, Boston, MA 02215, 1seidman@bidmc.harvard.edu. The views expressed are those of the authors and do not necessarily reflect the official views of the National Institute of Mental Health, the National Institutes of Health, or any other branch of the U.S. Department of Health and Human Services. 
Main Measures-A neurocognitive composite score, eight individual neuropsychological measures, an IQ estimate, and HR status.

Results-Global ("composite") neuropsychological functioning was comparably impaired in CHR and FHR groups compared to controls, but profiles differed significantly between groups. Neuropsychological functioning in the CHR group was significantly lower in persons who progressed to psychosis than in those who did not, and worst in the subgroup with a FH of psychosis. Tests of processing speed and verbal learning and memory were most sensitive in discriminating CHR from controls, although reductions were less severe than in established schizophrenia. Neuropsychological functioning did not contribute uniquely to the prediction of psychosis beyond clinical criteria, but worse verbal memory predicted more rapid conversion.

Conclusion-These findings document that CHR individuals have significant neuropsychological difficulties, particularly those who later develop psychosis. This dysfunction is generally of moderate severity but less than in first episode schizophrenia, suggesting that a further decline may occur after baseline CHR assessment.

Substantial neuropsychological deficits, first described by Kraepelin ${ }^{1}$ and Bleuler ${ }^{2}$, have subsequently been observed in all phases of schizophrenia, beginning in the premorbid period and continuing throughout life. Patients in the first psychotic episode and during chronic periods manifest large neuropsychological impairments with effect sizes (ES) averaging approximately $1.0^{3,4}$. The degree of impairment depends on the domain measured, with verbal memory and processing speed typically eliciting the largest deficits $(\mathrm{ES}=1.3-1.6 \text { using Cohen's } d)^{3,4}$. Moreover, because neuropsychological functions are important as windows into pathophysiology 5 and because they are strongly associated with functional outcomes in schizophrenia ${ }^{6}$, they may be important in risk prediction of psychosis.

The robust finding of premorbid neuropsychological impairment indicates that these measures may have utility as predictors of schizophrenia, an idea frequently evaluated in persons at genetic (familial) high risk ([F]HR $)^{7-9}$, and recently in clinical high risk (CHR) or putatively "prodromal" samples ${ }^{10}$. CHR requires the presence of specific subsyndromal psychotic symptoms, while FHR is defined solely by the presence of a family history (FH) of psychosis.

Compared to healthy control subjects, ESs of neuropsychological deficits in offspring ${ }^{8,9}$ and adult, non-psychotic relatives of persons with schizophrenia range between 0.3-0.6, reflecting moderate deficits in the absence of psychosis ${ }^{11-15}$. These findings suggest that cognitive deficits are associated with the neural substrates of the illness ${ }^{16-17}$ and that they may be attributable largely to inherited variations ${ }^{16,18}$. These impairments have considerable validity because they are not confounded by psychosis or medications. Commonly identified deficits in FHR samples include lower verbal ability, general intelligence ("IQ"), declarative and working memory, sustained attention, processing speed, executive and motor

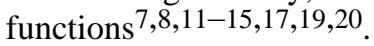

While identification of neuropsychological impairments in FHR studies supports a neurodevelopmental model of vulnerability to schizophrenia ${ }^{20-22}$, their utility for prediction of psychosis is limited by modest lifetime conversion rates of approximately $10 \%$. The problem of relatively low conversion rates in FHR samples and the notion that early detection and intervention may prevent clinical expression of psychosis or functional deterioration have stimulated a new direction in psychiatry research aimed at reducing morbidity and mortality ${ }^{23}$, similar to prevention efforts in other branches of medicine ${ }^{24,25}$. This approach has focused on developing and validating criteria for ascertaining individuals at risk for imminent onset of psychosis and following them over time ${ }^{26-28}$. Advantages of 
this approach over FHR methods include more efficient timing of assessments proximate to illness onset and reduction of false positive rates ${ }^{29,30}$. Because the modal period of onset in schizophrenia is between ages 18-30, "case identification" during adolescence and young adulthood is essential.

Over the past five years, at least 10 research groups have published studies of neuropsychological functioning in CHR samples ${ }^{10}$. Findings from cross-sectional CHR studies have consistently documented that neuropsychological deficits are intermediate between control and first episode psychosis samples ${ }^{10,31-54}$, and one has shown that neuropsychological functioning is related to illness course ${ }^{50}$. Several specific deficits have been observed, most reliably in spatial ${ }^{35-38}$ and verbal ${ }^{46}$ working memory, verbal declarative memory $39,40,43,52$, and attention ${ }^{31,32,40-44,48}$. Deficits in olfaction ${ }^{47}$ and executive functions, as measured by verbal fluency, matrices, and set-shifting, and visual form perception, have been less consistently tested or identified $31,32,35,36,40,43,46-48,52,54$. Some deficits (e.g., in sustained attention) may represent stable vulnerability markers ${ }^{40,41}$, while others (such as in verbal memory, working memory, processing speed and verbal $\mathrm{IQ}^{53}$ ) may be predictive of conversion to psychosis $39,40,48,49,53$.

Despite substantial progress, variability in test batteries and small samples complicate interpretation. Moreover, only two studies ${ }^{36,51}$ have integrated FHR and CHR methods, and the few studies that compared individuals who do and do not convert to illness are limited by small samples and brief follow-ups. Because many patients with neuropsychiatric disorders manifest neuropsychological deficits, it is important to compare those CHR individuals who develop psychosis with those who do not. Longitudinal designs including follow-up into conversion may identify neuropsychological deficits that predict psychosis.

The North American Prodrome Longitudinal Study (NAPLS) is a consortium of eight research centers, ascertaining CHR individuals and following them for a period of up to $2-1 / 2$ years $^{30,55,56}$. Although originally developed as independent studies, the sites employed similar ascertainment and diagnostic methods, making it possible to form a standardized protocol for mapping data into a new scheme representing the common components across sites ${ }^{30,55}$, yielding the largest database of longitudinally followed CHR cases worldwide.

The primary aims of this study are to characterize the neuropsychology of the psychosis prodrome by comparing CHR performance to normal controls and FHR, and to examine the value of neuropsychological function for predicting conversion to psychosis. Our hypotheses were that persons who subsequently convert to psychosis are more impaired at baseline than non-converters, that this effect would be amplified in persons with a FH of psychosis, and that poorer neuropsychological performance would predict more rapid conversion to psychosis.

\section{METHODS}

\section{Sample}

Study protocols and informed consent documents, including procedures for data pooling and secondary data analysis, were approved by the Institutional Review Boards of the participating sites (Emory University, Harvard University, University of California Los Angeles [UCLA], University of California San Diego [UCSD], University of North Carolina (UNC), University of Toronto (UT), Yale University, and Zucker Hillside Hospital in New York). NAPLS methods and details of the federated database not specific to the present study are described elsewhere ${ }^{30,55,56}$. Nine reports of neuropsychological function have been published on four smaller CHR samples by NAPLS centers: three from the PRIME 
multi-site study (including Yale, UNC and UT sites) ${ }^{31,32,33}$, two from Zucker-Hillside ${ }^{37,40}$, two from UCLA ${ }^{44,49}$ and two from UCSD ${ }^{48,49}$. However, these neuropsychological data were not previously combined, did not include a 2.5 year follow-up (a smaller PRIME study included 2-year follow-up ${ }^{33}$ ), and did not evaluate the impact of neuropsychological functioning on conversion to psychosis, in relation to $\mathrm{FH}$ and other possible predictors.

Participants from the NAPLS database who completed any baseline neuropsychological testing were included, yielding $304 \mathrm{CHR}$ individuals, 52 persons with a $\mathrm{FH}$ of psychosis without prodromal symptoms, and 193 normal controls without a FH of psychosis or prodromal symptoms. Of the 304 CHR subjects, 269 (89\%) were followed for up to 2-1/2 years to assess for conversion to psychosis. The 35 CHR participants without any follow-up were excluded from analyses that take conversion status into account. Of the $304 \mathrm{CHR}$ subjects, 89 (29\%) converted to psychosis, of whom $73(82 \%)$ had baseline neurocognitive data.

\section{Assessment Procedures}

The Structured Interview for Prodromal Syndromes (SIPS) $)^{57-58}$ criteria was used for study entry, and the Structured Clinical Interview for DSM-IV ${ }^{59}$ (SCID $)^{60}$ was most commonly used to assess general psychopathology. SIPS criteria ${ }^{57}$ for a CHR syndrome emphasize onset or worsening of attenuated positive symptoms in the past 12 months in at least one of five symptom domains: unusual thought content, suspicion/paranoia, grandiosity, perceptual anomalies, and disorganized communication. Subjects also qualified for a CHR syndrome if they showed onset of brief intermittent positive psychotic symptoms in the past 3 months but below the threshold required for a DSM-IV Axis I psychotic disorder diagnosis, or if they had a genetic risk for psychosis and deterioration of $30 \%$ or more on the Global Assessment of Functioning scale in the past 12 months, where genetic risk is defined by having a FH of psychosis or a diagnosis of schizotypal personality disorder. ${ }^{61,62}$ All NAPLS sites demonstrated good reliability employing the SIPS criteria ( $\kappa$ 's ranged from .80 to 1.00 across sites). ${ }^{57}$ At each site, raters were MA, PhD, or MD specialists in mental health.

\section{Follow-Up Assessments}

The SIPS was re-administered at 6-month intervals up to 30 months. If clinical deterioration was observed during interim periods, a re-assessment was conducted before regularly scheduled assessments. Because treatment was not standardized, information on dosing and duration of antipsychotic treatments was unavailable for the majority of cases.

\section{Baseline NAPLS Neuropsychological Assessment Protocol}

Cognitive performance variables presented unique challenges in the development of an omnibus protocol. ${ }^{57}$ Sixty-eight different neurocognitive measures derived from 40 separate tests were used across sites. Criteria for test inclusion in the federated database included: (1) representation across at least four sites, (2) comparability of test versions, administration procedures, and scoring, and (3) coverage of presumed areas of separable cognitive impairment in schizophrenia ${ }^{63}$. Thirteen cognitive variables, derived from 8 tests, were initially selected for the omnibus battery. However, to enhance commonality, to carry out multivariate statistical analyses and to create a composite score for use in prediction analyses, the number of variables examined in these analyses was reduced to eight: verbal comprehension (Vocabulary ${ }^{64-67}$ ), visual-perceptual-organization (Block Design ${ }^{64-66}$ ), vigilance (Continuous Performance Test - Identical Pairs [CPT-IP] digits ${ }^{68}$ ), speed of processing (Digit Symbol["Coding"] ${ }^{64-66}$ and Trail Making 69 B), executive functioning including verbal fluency (Controlled Oral Word Association [COWA] test ${ }^{70}$ ) and problem solving (Wisconsin Card Sorting Test [WCST] ${ }^{71-72}$ ), and verbal learning and memory (Story Recall tests from the Wechsler Memory Scales [WMS] ${ }^{73,74}$ for participants age 17 
and older and Children's Memory Scales [CMS] ${ }^{75}$ for those under age 17) and list learning on the Hopkins Verbal Learning Test (HVLT) ${ }^{76}$, Rey Auditory Verbal Learning Test $(\text { RAVLT })^{77}$, and California Verbal Learning Test (CVLT) adult and child versions ${ }^{78,79}$. Additional information regarding variable construction is available in an online supplement.

\section{Data Analytic Plan}

Data analyses consisted of two approaches: a univariate approach including all subjects for whom data was available in an individual cognitive domain, and a multivariate approach that included all cognitive domains and construction of a composite score. To support the multivariate approach, a series of decision rules for acceptable subject inclusion were created and imputation steps were implemented. This resulted in a multivariate sample $(n=325)$ that is a subset $(60 \%)$ of the univariate sample $(n=549)$, including reduced samples of CHR subjects ( $n=167,55 \%$ of the univariate sample), FHR ( $n=49,94 \%)$, and controls $(n=109,56 \%)$. Because of substantial subject loss in the multivariate sample, both samples were analyzed and compared. The univariate analyses are presented in an online supplement, and significant findings are integrated within the Results.

Formation of the Multivariate Sample-Inclusion in the multivariate sample required subjects to have a minimum of $75 \%$ complete data (i.e., completed at least 6 of 8 tests), thus reducing the total missing data to $<10 \%$, which was our maximum threshold for data loss prior to imputation. Multiple imputation (MI) methods were used to address missing data. In contrast to listwise deletion, which has the disadvantages of loss of observations and reduced statistical power, MI permits analysis of complete data by calculating estimates of missing values using other variables in the model as predictors ${ }^{80-82}$. Details of data imputation methods are in the online supplement.

Group Contrasts-The groups compared were CHR, FHR and normal controls (NC). The CHR group was further subdivided into converters to psychosis (CHR+) and nonconverters (CHR-). Six comparisons were made within both the multivariate and univariate samples: 1). CHR vs. NC; 2). FHR vs. NC; 3). CHR vs. FHR; 4). CHR+ vs. NC; 5). CHRvs. $\mathrm{NC} ; 6)$. $\mathrm{CHR}+$ vs. $\mathrm{CHR}-$. A small subgroup of $\mathrm{CHR}+$ with a positive $\mathrm{FH}(\mathrm{CHR}+\mathrm{FH}+)$ were analyzed within the univariate sample, due to its larger $\mathrm{CHR}+\mathrm{FH}+$ sub-sample.

Statistical Analyses-Statistical analyses were performed using SPSS version 17 or SAS version 9.1. One-way analysis of variance (ANOVA) and chi-square tests were conducted to compare groups on demographics. For the multivariate sample, comparison of neuropsychological measures was conducted using multivariate ANOVA (MANOVA), multivariate analysis of covariance (MANCOVA), univariate ANCOVA, and Profile Analysis.

In some contrasts, groups were significantly different on education, parental education, gender and ethnicity. Because ethnicity and parental education were correlated, and because parental education is strongly associated with neurocognition, parental education was controlled. In contrast, subjects' own education is likely to be affected by illness and was not controlled. Because small differences in age can influence neuropsychological functioning in adolescence, analyses controlled for age, parental education and gender. We also tested for the effects of "site". To examine whether neuropsychological impairments were significant beyond general intellectual impairment, we used MANCOVA controlling for age, gender and FSIQ estimate ${ }^{83}$ (after removing Vocabulary and Block Design tests that comprise estimated FSIQ from the profiles). To test whether the shape of neuropsychological profiles differed for selected contrasts, unadjusted scores were analyzed using the General Linear Model repeated measures function. For profile analyses, the 8 
measures were standardized against the normal controls within each of the 5 imputed datasets and then pooled across imputed datasets. In addition, a composite score was constructed as the mean of the 8 standardized scores within each imputed dataset and then pooled.

Statistical significance was set at $p<.05$ using 2-tailed tests for multivariate analyses (MANOVA, MANCOVA, profile analyses, Composite score). Bonferroni correction was used to control the Type I error rate for univariate analyses $(.05 / 8$ or $<=.00625)$. Comparisons that remained significant at the Bonferroni-corrected level are bolded in the tables and presented in Results. ESs (unadjusted) were calculated with Cohen's $d^{84}$.

Primary analyses were followed by tests of association between neurocognitive functioning and psychosis progression for the multivariate sample. To identify the cognitive variables most predictive of psychosis progression, we first examined the predictive value of the baseline composite score, FSIQ, Coding and Verbal Memory in separate Cox regression models. The latter three were chosen because they are most sensitive in FHR and schizophrenia patients respectively $3,4,8$. A multivariate Cox regression using backward selection was conducted to identify which of the 8 cognitive test scores have unique predictive associations with conversion. A second set of multivariate Cox regressions were used to determine whether any of the 10 cognitive variables added unique prediction beyond the multivariate NAPLS clinical algorithm previously reported. ${ }^{30}$

\section{RESULTS}

\section{Demographic Characteristics}

Multivariate Sample-Comparing CHR and FHR participants with controls revealed no significant group differences in age (Table 1 and Table S1). CHR subjects attained significantly less education than controls. The FHR group showed significantly less parental education than controls. The CHR group had significantly fewer females than the FHR and control groups. The groups differed on race, with significantly more Caucasians in CHR than other groups. Parental education was significantly lower in CHR+ than in $\mathrm{CHR}-$.

Univariate Sample-Demographic comparisons were the same in the univariate and multivariate sample comparisons with the following additions: 1. Parental education was significantly lower in the CHR group than in controls; 2 . There were significantly fewer African Americans in CHR than other groups; 3. The FHR group had significantly fewer Asian Americans than other groups; 4. CHR+ and CHR- did not differ significantly on any variable.

The 167 CHR multivariate subjects did not differ significantly on any demographic variable compared to the additional $137 \mathrm{CHR}$ subjects who together formed the univariate sample.*

\section{Neuropsychological Functioning \\ 1. CHR vs. Controls}

Multivariate: Raw data are presented in Table 2 and statistical results in Table 3. The MANOVA and MANCOVA for the 8 tests were statistically significant. The MANCOVA, controlling for FSIQ (covariate $F=0.26, p=.619, d=.16$ ), was significant and Coding $(d=$. 56), COWA $(d=.48)$, Verbal Memory $(d=.45)$, CPT-IP $(d=.39)$ and the composite score $(d=.45)$ were significant. See Figure 1 for profile.

\footnotetext{
* Results available on request from the first author.
} 
Univariate: Raw data are presented in Table S2 and results in Table S3. Significant tests are Coding $(d=.58)$, Verbal Memory $(d=.54)$, COWA $(d=.47)$ and CPT-IP digits $(d=.43)$.

\section{FHR vs. Controls}

Multivariate: The MANOVA and MANCOVA were statistically significant. The MANCOVA controlling for FSIQ (covariate $F=8.76, p=.004 ; d=.70$ ) was not significant. Vocabulary $(d=.70)$, Coding $(d=.66)$ and the composite score $(d=.75)$ were significant. See Figure 1 for profile.

Univariate: Significant tests were Vocabulary $(d=.89)$, Coding $(d=.66)$ and COWA $(d=$. 59).

\section{CHR vs. FHR}

Multivariate: The MANOVA and MANCOVA were statistically significant. The MANCOVA controlling for FSIQ (covariate $F=4.07, p=.045 ; d=.44$ ) was significant. Verbal Memory $(d=.40)$ was significant. The composite score was not significant $(d=.16)$. Comparing CHR vs. FHR, a test by group interaction was observed $(F=4.99, p<.001)$, indicating a differential (i.e., non-parallel) pattern of scores (Figure 1). There was no main effect for group, indicating comparable overall performance $(F=0.06, p=.819)$. Table 3 shows that the differential pattern of performance is accounted for by FHR exhibiting somewhat greater impairment on Vocabulary, while CHR exhibited significantly greater impairment in Verbal Memory.

Univariate: No tests were significantly different.

\section{CHR+ vs. Controls}

Multivariate: The MANOVA and MANCOVA were statistically significant. The MANCOVA controlling for FSIQ (covariate $F=2.34, p=.128 ; d=.34$ ) was significant. Coding $(d=.69)$, Verbal Memory $(d=.65)$, Vocabulary $(d=.50)$ and the composite score were significant $(d=.72)$. See Figure 1 for profile.

Univariate: Verbal Memory $(d=.79)$, Coding $(d=.68)$, COWA $(d=.68)$, Vocabulary $(d=$ $65)$ and CPT-IP digits $(d=.62)$ were significant.

\section{CHR- vs. Controls}

Multivariate: The MANOVA and MANCOVA were statistically significant. The MANCOVA controlling for FSIQ (covariate $F=0.05, p=.838 ; d=.07$ ) was significant. Coding $(d=.50)$ was significant. The composite score was not significant $(d=.36)$. See Figure 1 for profile.

Univariate: Significant tests were Coding $(d=.57)$, Verbal Memory $(d=.46)$ and CPT-IP digits $(d=.39)$.

\section{CHR+ vs. CHR-}

Multivariate: The MANOVA was significant and the MANCOVA showed a marginal trend $(p=.08)$. The MANCOVA controlling for FSIQ (covariate $F=1.90, p=.170 ; d=.26$ ) was not significant. The composite score $(d=.40)$ and Vocabulary $(d=.46)$ were significant. A test of profile shape showed no significant test-by-group interaction $(F=1.65, p=.136)$. A main effect of test was observed $(F=8.56, p<.001)$, indicating that differential performance was observed across tests, independent of the groups. In addition, there was a 
main effect of group, indicating that the profiles differed in overall neuropsychological performance $(F=6.47, p=.012)$. See Figure 1 .

Univariate: Vocabulary was significant $(d=.43)$.

\section{7. $\mathrm{CHR}+\mathrm{FH}+$ vs. Controls}

Univariate: Because the sample was small $(\mathrm{CHR}+\mathrm{FH}+$ maximum $\mathrm{n}=13)$, only the univariate sample data was analyzed. Statistically significant, large effects were obtained on Verbal Memory $(d=.99)$, CPT-IP digits $(d=.98)$, and Coding $(d=.87)$. The overall mean ES, weighted for the sample size for each test, suggests a dose response and is largest in $\mathrm{CHR}+\mathrm{FH}+$ (Figure 2).

Site: Although group ascertainment differed significantly by site (see online supplement), MANCOVAs using site showed minimal impact, affecting only one of six contrasts (CHR+ vs. CHR-; Table 3).

Sensitivity of Individual Tests: $12 / 48$ tests (25\%) in the multivariate sample and 16/48 tests $(33 \%)$ in the univariate sample (which included $45 \%$ more subjects) were statistically significant at the Bonferroni level. Coding was significant 4/6 times and Verbal Memory was significant $3 / 6$ times in each sample, indicating that they were most likely to show impairment. Block Design, Trail Making B, and WCST perseverations were not significant at the Bonferroni level in any comparisons, suggesting they are less affected in HR samples.

Prediction of Progression to Psychosis with Neuropsychological Tests: Cox regression models were estimated to identify baseline cognitive variables that were most predictive of time to conversion to psychosis. In the first set of analyses, only four selected variables were examined. The composite score $\left(\chi^{2}(1)=3.05, p=0.08\right)$, FSIQ $\left(\chi^{2}(1)=2.63, p=0.11\right)$, and Coding $\left(\chi^{2}=0.14, p=0.71\right)$ were not significant. In contrast, Verbal Memory was a significant predictor of time to conversion $\left(\chi^{2}=6.1, p=0.01\right)$, and demonstrated a hazard ratio of 0.79 suggesting that $\mathrm{CHR}$ subjects with impaired verbal memory were likely to progress more rapidly to psychosis. A second analysis used backward selection to identify which among the eight cognitive variables were the best predictors of rate of progression to psychosis. The log rank test was not significant $\left(\chi^{2}(1)=13.18, p=0.11\right)$. A third Cox regression examined whether the cognitive variables (composite, FSIQ, Coding, and Verbal Memory) added to the multivariate NAPLS prediction model ${ }^{30}$. None contributed uniquely to the prediction of psychosis beyond clinical variables.

\section{Discussion}

As predicted, CHR subjects were significantly impaired in neuropsychological functioning compared to controls after statistically adjusting for age, gender and parental education, and site, as well as for IQ, indicating that impairments were not simply a general intellectual deficit. Impairments were significantly more severe in CHR+ than CHR- but modestly so (composite score $d=.40$ ), suggesting that neuropsychological deficits are associated strongly with risk states for psychosis and additionally with conversion. CHR and FHR groups were similarly impaired in composite neuropsychological functioning relative to controls, but their profiles differed distinctly. Thus, risk status based on clinical symptoms and FH both index neuropsychological vulnerability to psychosis, but they appear to be characterized by different impairments. Impairments were most severe in the converters who also had a FH of psychosis, suggesting a synergistic, dose-response effect (Figure 2), although this group was quite small and this result requires replication. Tests of verbal learning and memory and processing speed were most sensitive in discriminating CHR and 
control groups, and verbal memory predicted more rapid conversion. However, neuropsychological measures did not significantly enhance the NAPLS clinical prediction algorithm reported previously ${ }^{30}$.

The severity and pattern of impairment in CHR compared to results from first episode psychosis (FE) studies is informative (see Table 4). First, it is of interest that the two most impaired tests found in FE samples, Coding and Verbal Memory, were the two most impaired tests in our CHR+ sample. These tasks rely heavily on verbal skills, processing speed and new learning, functions that are reliably impaired in schizophrenia, and clearly presage the disorder. Second, tasks such as Block Design, Trail Making B, and WCST, though impaired in FE samples, were less sensitive measures in CHR+ subjects. Tasks that are more visual and less verbal in nature, and explicitly require executive functions, were affected somewhat less than verbal tasks. Alternatively, the psychometric characteristics of Verbal Memory and Coding tests may be superior to other measures, making them more sensitive to the presence of deficits of any severity. However, because most clinical neuropsychological tests are multifactorial, more refined cognitive neuroscience measures are needed to determine which cognitive mechanisms are impaired.

From a staging perspective, as further explicated in Table 4, neurocognitive deficit apparently increases in severity from prodrome to $\mathrm{FE}$, and this growing impairment is accompanied by increasing executive dysfunction ${ }^{4}$. This suggests that additional neuropsychological deterioration in those developing psychosis may continue to occur during the late prodromal phase, and possibly during and subsequent to the first episode of psychosis. However, this proposition can only be addressed definitively in longitudinal studies that monitor cognitive function in the same subjects. The literature on this issue is quite sparse, with only one published study having similar neuropsychological data collected relatively close to and after the first episode; significant decline was reported on two of the four tests ${ }^{85}$.

A major strength of this study is its large sample size, larger at baseline and follow-up than any previously published study of neurocognition in CHR individuals. Very few published reports on CHR have included neuropsychological functioning in persons who convert to psychosis $32,33,39,40,48,49,53$. With the exception of the Melbourne $(n=34)^{39}$ and German $(n=44)^{52}$ projects, sample sizes are small ( $<21$ converters). Thus, this study, which compared neuropsychological functioning on as many as 71 converters, provides the most robust data indicating that persons who later convert to psychosis are especially impaired at baseline (composite $d=.72$ ). While the overall (composite) ES difference between CHR+ and CHR - was modest $(d=.40)$, the effect was consistent in that CHR+ performed worse than CHR- on all 8 neuropsychological measures. Based on the Cox regression analyses, only verbal memory was associated with a significant increase in time to conversion. When the 8 neurocognitive variables, FSIQ, or the composite score were added separately to the multivariate NAPLS prediction algorithms ${ }^{30}$, none of the prediction statistics for the neurocognitive variables were significant, indicating that none added unique variance to prediction beyond clinical variables. It remains possible that future large-scale studies that include a uniformly broader range of neuropsychological tests, particularly measures of olfaction and working memory (shown in prior studies to be associated with conversion but unavailable in this data set), may add unique predictive power to risk algorithms.

The neuropsychological functioning of the FHR sample was consistent with the extant literature, yielding ES differences of .20 to. 70 for many functions. This suggests that a modest proportion of the variance in neuropsychological function is putatively associated

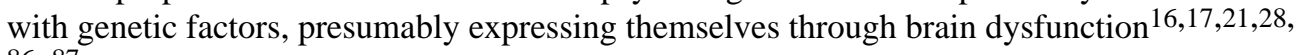
86-87. What is striking about our findings is that CHR and FHR had different patterns of 
impairment, and thus FHR may contribute additional cognitive impairments to CHR status. This was observed in the larger ESs in the $\mathrm{CHR}+\mathrm{FH}+$ subgroup, although small sample size precludes firm conclusions. Only two studies have linked FH and conversion to psychosis, the Edinburgh ${ }^{50}$ and Palau ${ }^{36}$ HR studies. These studies used very different designs and ascertainment criteria, making findings difficult to integrate. Nonetheless, both studies show a trend for persons with FHR plus prodromal symptoms to be particularly neuropsychologically impaired.

This study has a number of limitations, the most important being variability in the specific tests administered across NAPLS sites resulting in relatively high rates of missing data for some measures and inconsistent sample sizes across tests. We addressed this problem by creating a multivariate sample in which we reduced the number of tests and subjects, and imputed data. Although this resulted in substantial subject loss, we were able to demonstrate that the results were quite consistent across the smaller multivariate subsample and the full univariate sample as observed by comparable ESs (see Table 4). We also constrained our conclusions about individual tests with Bonferroni corrections. Another limitation was the domains assessed (e.g., social cognition, olfaction, and other measures of executive function were not assessed). Future work should combine large samples with a common neuropsychological battery, selected to maximize predictive value. In addition, because it is quite likely that some CHR will convert to psychosis later ${ }^{88}$, "misclassifying" some subjects as "non-converters" may have reduced the differences observed in CHR+ and CHRcontrasts. Subjects were followed up for variable periods, but even a 2.5 year follow-up duration is unlikely to identify all persons who convert. We also had limited data on medication status and other treatment exposures. It will be important in future CHR studies to account for the effects of psychopharmacological and other treatments.

Despite these limitations, our study is largely consistent with the results of other research groups, including those comparing converters vs. non-converters ${ }^{53}$. These findings demonstrate that prospective ascertainment of individuals at CHR for psychosis reveals significant neuropsychological impairment, especially among those who later convert to psychosis, and these effects are amplified among those with a FH of psychosis. Because neuropsychological tests are relatively inexpensive, have extensive normative data, and are heavily used by school personnel, in conjunction with FH and attenuated clinical symptoms, they may have potential as early indicators of risk for psychosis as well as other important outcomes such as functional disability.

\section{Supplementary Material}

Refer to Web version on PubMed Central for supplementary material.

\section{Acknowledgments}

The authors acknowledge the substantial contributions of Jennifer Johnson (UCLA), Diane Kirsopp (Toronto), and Roy Money (Yale) to the creation of the federated NAPLS database described in this paper.

\section{References}

1. Kraepelin, E. Dementia praecox and paraphrenia. Edinburgh: E. \& S. Livingston; 1919.

2. Bleuler, E. Dementia praecox or the group of schizophrenias. New York, NY: International Universities Press; 1950.

3. Heinrichs RW, Zakzanis KK. Neurocognitive deficits in schizophrenia: A quantitative review of the evidence. Neuropsychology. 1998; 12:426-445. [PubMed: 9673998] 
4. Mesholam-Gately R, Giuliano AJ, Goff KP, Faraone SV, Seidman LJ. Neurocognition in firstepisode schizophrenia: A meta-analytic review. Neuropsychology. 2009; 23:315-336. [PubMed: 19413446]

5. Seidman LJ. Schizophrenia and brain dysfunction: An integration of recent neurodiagnostic findings. Psychological Bulletin. 1983; 94:195-238. [PubMed: 6356196]

6. Green M. What are the functional consequences of neurocognitive deficits in schizophrenia? Am J Psychiatry. 1996; 153:321-330. [PubMed: 8610818]

7. Cornblatt B, Erlenmeyer-Kimling L. Global attentional deviance as a marker of risk for schizophrenia: specificity and predictive validity. J Abnorm Psychol. 1985; 94:470-486. [PubMed: 3865953]

8. Woodberry K, Giuliano AJ, Seidman LJ. Premorbid IQ in schizophrenia: A meta-analytic review. Am J Psychiatry. 2008; 165:579-87. [PubMed: 18413704]

9. Niemi L, Suvisaari J, Tuulio-Henriksson A, Lonnqvist J. Childhood developmental abnormalities in schizophrenia: evidence from high-risk studies. Schizophr Res. 2003; 60:239-258. [PubMed: 12591587]

10. Brewer WJ, Wood SJ, Phillips LJ, Francey SM, Pantelis C, Yung AR, Cornblatt B, McGorry PD. Generalized and specific cognitive performance in clinical high-risk cohorts: A review highlighting potential vulnerability markers for psychosis. Schizophr Bull. 2006; 32:538-555. [PubMed: 16782759]

11. Kremen WS, Seidman LJ, Pepple JR, Lyons MJ, Tsuang MT, Faraone SV. Neuropsychological risk indicators for schizophrenia: a review of family studies. Schizophr Bull. 1994; 20:96-108.

12. Sitskoorn MM, Aleman A, Ebisch SJ, Appels MC, Kahn RS. Cognitive deficits in relatives of patients with schizophrenia: a meta-analysis. Schizophr Res. 2004; 71:285-295. [PubMed: 15474899]

13. Snitz BE, Macdonald AW 3rd, Carter CS. Cognitive deficits in unaffected first-degree relatives of schizophrenia patients: a meta-analytic review of putative endophenotypes. Schizophr Bull. 2006; 32:179-194. [PubMed: 16166612]

14. Trandafir A, Méarya A, Schürhoffa F, Leboyera M, Szöke A. Memory tests in first-degree adult relatives of schizophrenic patients: A meta-analysis. Schizophr Res. 2006; 81:217-226. [PubMed: 16246526]

15. Szoke A, Schurhoff F, Mathieu F, Meary A, Ionescu S, Leboyer M. Test of executive functions in first-degree relatives of schizophrenic patients. Psychol Medicine. 2005; 35:771-782.

16. Gottesman II, Gould TD. The endophenotype concept in psychiatry: Etymology and strategic intentions. Am J Psychiatry. 2003; 160:636-645. [PubMed: 12668349]

17. Gur RE, Calkins ME, Gur RC, Horan WP, Nuechterlein KH, Seidman LJ, Stone WS. The consortium on the genetics of schizophrenia: Neurocognitive endophenotypes. Schizophr Bull. 2007; 33:49-68. [PubMed: 17101692]

18. Harrison PJ, Weinberger DR. Schizophrenia genes, gene expression, and neuropathology: on the matter of their convergence. Mol Psychiatry. 2005; 10:40-68. [PubMed: 15263907]

19. Seidman LJ, Giuliano AJ, Smith CW, et al. Neuropsychological functioning in adolescents and young adults at genetic risk for schizophrenia and affective psychoses: results from the Harvard and Hillside adolescent high risk studies. Schizophr Bull. 2006; 32:507-24. [PubMed: 16707777]

20. Nuechterlein KH, Dawson ME. Information processing and attentional functioning in the developmental course of schizophrenia disorders. Schizophr Bull. 1984; 10:160-203. [PubMed: 6729409]

21. Seidman LJ. The neuropsychology of schizophrenia: A neurodevelopmental and case study approach. J Neuropsychiat Clin Neurosci. 1990; 2:301-312.

22. Cornblatt BA, Lencz T, Smith CE, Correll CU, Auther AM, Nakayama E. The schizophrenia prodrome revisited: a neurodevelopmental perspective. Schizophr Bull. 2003; 29:633-651. [PubMed: 14989404]

23. Insel TR. Cure therapeutics and strategic prevention: raising the bar for mental health research. Mol Psychiatry. 2006; 11:11-17. [PubMed: 16355250]

24. Peters AL, Davidson MB, Schriger DL, Hasselblad V. A clinical approach for the diagnosis of diabetes mellitus: an analysis using glycosylated hemoglobin levels. Meta-analysis Research 
Group on the Diagnosis of Diabetes Using Glycated Hemoglobin Levels. JAMA. 1996; 276:124652. [PubMed: 8849753]

25. Adams EK, Breen N, Joski PJ. Impact of the National Breast and Cervical Cancer Early Detection Program on mammography and pap test utilization among white, Hispanic, and African American women: 1996-2000. Cancer. 2007; 109:348-58. [PubMed: 17136766]

26. Yung AR, McGorry PD. The prodromal phase of first-episode psychosis: Past and current conceptualizations. Schizophr Bull. 1996; 22:353-370. [PubMed: 8782291]

27. McGlashan TH, Johannessen JO. Early detection and intervention with schizophrenia: Rationale. Schizophr Bull. 1996; 22:201-222. [PubMed: 8782282]

28. Cornblatt B. From the prediction of schizophrenia to prevention: the New York High Risk Project to the Hillside Recognition and Prevention (RAP) Program. Neuropsychiatric Genetics. 2002; 114:956-966. [PubMed: 12457393]

29. Cannon TD. Clinical and genetic high-risk strategies in understanding vulnerability to psychosis. Schizophr Res. 2005; 79:35-44. [PubMed: 16054805]

30. Cannon TD, Cadenhead KS, Cornblatt B, Woods SW, Addington J, Walker EF, Seidman LJ, Perkins DO, Tsuang MT, McGlashan TH, Heinssen R. Prediction of psychosis in youth at high clinical risk: A multi-site longitudinal study in North America. Arch Gen Psychiatry. 2008; 65:2837. [PubMed: 18180426]

31. Hawkins KA, Addington J, Keefe RSE, Christensen B, Perkins DO, Zipursky R, Woods SW, Miller TJ, Marquez A, Brier A, McGlashan TH. Neuropsychological status of subjects at high risk for a first episode of psychosis. Schizophr Res. 2004; 67:115-122. [PubMed: 14984870]

32. Keefe RSE, Perkins DO, Gu H, Zipursky RB, Christensen BK, Lieberman JA. A longitudinal study of neurocognitive function in individuals at-risk for psychosis. Schizophr Res. 2006; 88:26-35. [PubMed: 16930949]

33. Hawkins KA, Keefe RS, Christensen BK, Addington J, Woods SW, Callahan J, Zipursky RB, Perkins DO, Tohen M, Breier A, McGlashan TH. Neuropsychological course in the prodrome and first episode of psychosis: findings from the PRIME North America Double Blind Treatment Study. Schizophr Res. 2008; 105(1-3):1-9. [PubMed: 18774696]

34. Silverstein S, Uhlhaas PJ, Essex B, Halpin S, Schall U, Carr V. Perceptual organization in first episode schizophrenia and ultra-high-risk states. Schizophr Res. 2006; 83:41-52. [PubMed: 16497484]

35. Bartok E, Berecz R, Glaub T, Degrell I. Cognitive functions in prepsychotic patients. Prog Neuropsychopharmacol Biol Psychiatry. 2005; 29:621-625. [PubMed: 15866367]

36. Myles-Worsley M, Ord LM, Ngiralmau H, Weaver S, Blailes F, Faraone SV. The Palau Early Psychosis Study: Neurocognitive functioning in high-risk adolescents. Schizophr Res. 2007; 89:299-307. [PubMed: 17005375]

37. Smith CW, Park S, Cornblatt B. Spatial working memory deficits in adolescents at clinical high risk for schizophrenia. Schizophr Res. 2006; 81:211-215. [PubMed: 16321508]

38. Wood SJ, Pantelis C, Proffitt T, Phillips LJ, Stuart GW, Buchanan J, Mahony K, Brewer WJ, Smith D, McGorry PD. Spatial working memory ability is a marker of risk-for-psychosis. Psychol Med. 2003; 33:1239-1247. [PubMed: 14580078]

39. Brewer WJ, Francey SM, Wood SJ, Jackson HJ, Pantelis C, Phillips LJ, Yung AR, Anderson VA, McGorry PD. Memory impairments identified in people at ultra-high risk for psychosis who later develop first-episode psychosis. Am J Psychiatry. 2005; 162:71-78. [PubMed: 15625204]

40. Lencz T, Smith CW, McLaughlin D, Auther A, Nakayama E, Hovey L, Cornblatt BA. Generalized and specific neurocognitive deficits in prodromal schizophrenia. Biol Psychiatry. 2006; 59:863871. [PubMed: 16325151]

41. Francey SM, Jackson HJ, Phillips LJ, Wood SJ, Yung AR, McGorry PD. Sustained attention in young people at high risk of psychosis does not predict transition to psychosis. Schizophr Res. 2005; 79:127-136. [PubMed: 16107309]

42. Gschwandtner U, Pflueger M, Aston J, Borgwardt S, Drewe M, Stieglitz RD, Riecher-Rossler A. Fine motor function and neuropsychological deficits in individuals at risk for schizophrenia. Eur Arch Psychiatry Clin Neurosci. 2005; 256:201-206. [PubMed: 16283597] 
43. Hambrecht M, Lammertink M, Klosterkotter J, Matuschek E, Pukrop R. Subjective and objective neuropsychological abnormalities in a psychosis prodrome clinic. Br J Psychiatry. 2002; 181(Suppl 43):s30-s37.

44. Niendam TA, Bearden CE, Johnson JK, McKinley M, Loewi R, O’Brien M, Nuechterlein KN, Green MF, Cannon TD. Neurocognitive performance and functional disability in the psychosis prodrome. Schizophr Res. 2006; 84:100-111. [PubMed: 16563699]

45. Gschwandtner U, Aston J, Borgwaldt S, Drewe M, Feinendegen C, Lacher D, Lanzarone A, Stieglitz RD, Riecher-Rossler A. Neuropsychological and neurophysiological findings in individuals suspected to be at risk for schizophrenia: Preliminary results from the Basel early detection of psychosis study-Fruherkennung von Psychosen (FEPSY). Acta Psychiatr Scandinavia. 2003; 108:152-155.

46. Pflueger M, Gschwandtner U, Stieglitz RD, Riecher-Rossler A. Neuropsychological deficits in individuals with an at risk metal state for psychosis: working memory as a potential trait marker. Schizophr Res. 2007; 97:14-24. [PubMed: 17936587]

47. Brewer WJ, Wood SJ, McGorry PD, Francey SM, Phillips LJ, Yung AR, Anderson V, Copolov DL, Singh B, Velakoulis D, Pantelis C. Impairment of olfactory identification ability in individuals at ultra-high risk for psychosis who later develop schizophrenia. Am J Psychiatry. 2003; 160:1790-1794. [PubMed: 14514492]

48. Eastvold AD, Heaton RK, Cadenhead KS. Neurocognitive deficits in the (putative) prodrome and first episode of psychosis. Schizophr Res. 2007; 93:266-277. [PubMed: 17467955]

49. Jashan C, Heaton RK, Golshan S, Cadenhead KS. Course of neurocognitive deficits in the prodrome and first episode of schizophrenia. Neuropsychology. In Press.

50. Niendam TA, Bearden CE, Zinberg J, Johnson JK, O'Brien M, Cannon TD. The course of neurocognition and social functioning in individuals at ultra high risk for psychosis. Schizophr Bull. 2007; 33:772-781. [PubMed: 17420177]

51. Cosway R, Byrne M, Clafferty R, et al. Neuropsychological change in young people at high risk for schizophrenia: Results from the first two neuropsychological assessments of the Edinburgh High Risk Study. Psychol Med. 2000; 30:1111-1121. [PubMed: 12027047]

52. Pukrop R, Schultze-Lutter F, Ruhrmann S, Brockhaus-Dumke A, Tendolkar I, Bechdolf A, Matuschek E, Klsoterkotter J. Neurocognitive functioning in subjects at risk for a first episode of psychosis compared with first- and multiple-episode schizophrenia. J Clin Exp Neuropsychol. 2006; 28:1388-1407. [PubMed: 17050266]

53. Pukrop R, Ruhrmann S, Schultze-Lutter F, Bechdolf A, Brockhaus-Dumke A, Klosterkötter J. Neurocognitive indicators for a conversion to psychosis: Comparison of patients in a potentially initial prodromal state who did or did not convert to a psychosis. Schizophr Res. 2007; 92:116125. [PubMed: 17344028]

54. Kimhy D, Corcoran C, Harkavy-Friedman JM, Ritzler B, Javitt DC, Malaspina D. Visual form perception: A comparison of individuals at high risk for psychosis, recent onset schizophrenia and chronic schizophrenia. Schizophr Res. 2007; 97:25-34. [PubMed: 17884347]

55. Addington J, Cadenhead KS, Cannon TD, Cornblatt B, McGlashan TH, Perkins DO, Seidman LJ, Tsuang MT, Walker EF, Woods SW, Heinssen R. on behalf of the NAPLS group. North American Prodrome Longitudinal Study (NAPLS): A collaborative multi-site approach to prodromal Schizophrenia. Schizophr Bull. 2007; 33:665-672. [PubMed: 17255119]

56. Woods SW, Addington J, Cadenhead KS, Cannon TD, Cornblatt BA, Heinssen R, Perkins DO, Seidman LJ, Tsuang MT, Walker EF, McGlashan TH. Validity of the prodromal risk syndrome for first psychosis: Findings from the North American Prodrome Longitudinal Study. Schizophr Bull. 2009; 35:894-908. [PubMed: 19386578]

57. Miller TJ, McGlashan TH, Rosen JL, Cadenhead K, Cannon T, Ventura J, Macfarlane W, Perkins DO, Pearlson GD, Woods SW. Prodromal assessment with the structured interview for prodromal syndromes and the scale of prodromal symptoms: predictive validity, interrater reliability, and training to reliability. Schizophr Bull. 2003; 29:703-15. [PubMed: 14989408]

58. Miller TJ, McGlashan TH, Rosen JL, Somjee L, Markovich PJ, Stein K, Woods SW. Prospective diagnosis of the initial prodrome for schizophrenia based on the Structured Interview for Prodromal Syndromes: preliminary evidence of interrater reliability and predictive validity. Am J Psychiatry. 2002; 159:863-5. [PubMed: 11986145] 
59. American Psychiatric Association (APA). Diagnostic and Statistical Manual of Mental Disorders. 4. Washington DC: 1994.

60. Spitzer, RL.; Williams, JB.; Gibbon, M. Instruction Manual for the Structured Clinical Interview for DSM-IV. New York, NY: Biometrics Research Department, New York State Psychiatric Institute; 1994.

61. Kendler KS, Gruenberg AM, Strauss JS. An independent analysis of the Copenhagen sample of the Danish adoption study of schizophrenia. II. The relationship between schizotypal personality disorder and schizophrenia. Arch Gen Psychiatry. 1981; 38:982-4. [PubMed: 7283669]

62. Siever L, Davis K. The pathophysiology of schizophrenia disorders: perspectives from the spectrum. Am J Psychiatry. 2004; 161:398-413. [PubMed: 14992962]

63. Nuechterlein KH, Barch DM, Gold JM, Goldberg TE, Green MF, Heaton RK. Identification of separable cognitive factors in schizophrenia. Schizophr Res. 2004; 72:29-39. [PubMed: 15531405]

64. Wechsler, D. Manual for the Wechsler Intelligence Scale for Children. 3. San Antonio, TX: The Psychological Corporation; 1991.

65. Wechsler, D. Manual for the Wechsler Adult Intelligence Scale-Revised. San Antonio, TX: The Psychological Corporation; 1981.

66. Wechsler, D. Wechsler Adult Intelligence Scale. 3. San Antonio, TX: The Psychological Corporation; 1997.

67. Wechsler, D. Manual for the Wechsler Abbreviated Intelligence Scale (WASI). San Antonio, TX: The Psychological Corporation; 1999.

68. Cornblatt B, Risch N, Faris G, Friedman D, Erlenmeyer-Kimling L. The Continuous Performance Test, Identical Pairs version (CPT-IP): I. New findings about sustained attention in normal families. Psychiatr Res. 1988; 26:223-238.

69. Reitan, R.; Wolfson, D. The Halstead-Reitan Neuropsychological Test Battery: Theory and clinical interpretation. 2. S. Tucson, AZ: Neuropsychology Press; 1993.

70. Benton, A.; Hamsher, K.; Sivan, A. Multilingual Aphasia Examination. 3. Iowa City, IA: AJA Associates; 1983.

71. Heaton, RK.; Chelune, GJ.; Talley, JL.; Kay, GG.; Curtiss, G. Wisconsin Card Sort Test Manual: Revised and Expanded. Odessa, FL: Psychological Assessment Resources, Inc; 1993.

72. Kongs, SK.; Thompson, LL.; Iverson, GL.; Heaton, RK. Wisconsin Card Sorting Test-64 Card Version. Lutz, FL: Psychological Assessment Resources; 2000.

73. Wechsler, D. The Wechsler Memory Scale-Revised: Manual. San Antonio, TX: The Psychological Corporation; 1987.

74. Wechsler, D. Manual for the Wechsler Memory Scale. 3. San Antonio, TX: The Psychological Corporation; 1997.

75. Cohen, M. Children's Memory Scale. San Antonio, TX: The Psychological Corporation; 1997.

76. Brandt, J.; Benedict, RHB. Hopkins Verbal learning Test- Revised (HVLT-R). Odessa, FL: Psychological Assessment Resources, Inc; 1998.

77. Lezak, MD. Neuropsychological Assessment. 3. Oxford University Press; New York: 1995.

78. Delis, DC.; Kramer, JH.; Kaplan, E.; Ober, BA. California Verbal Learning Test. 2. San Antonio, TX: The Psychological Corp; 2000.

79. Delis, D.; Kramer, J.; Kaplan, E.; Ober, B. The California Verbal Learning Test - Children's Version. San Antonio: Psychological Corporation; 1994.

80. Rubin, DB. Multiple imputation for nonresponse in surveys. New York: John Wiley \& Sons; 1987.

81. Little, RJA.; Rubin, DB. Statistical analysis with missing data. New York: John Wiley \& Sons; 2002.

82. Schafer JL, Graham JW. Missing data: Our view of the state of the art. Psych Methods. 2003; 7:147-177.

83. Brooker BH, Cyr JJ. Tables for clinicians to use to convert WAIS-R short forms. J Clin Psych. 1986; 42:982-986.

84. Cohen, J. Statistical power analysis for the behavioral sciences. 2. Hillsdale, NJ: Earlbaum; 1988. 
85. Caspi A, Reichenberg A, Weiser M, Rabinowitz J, Kaplan Z, Knobler H, Davidson-Sagi N, Davidson M. Cognitive performance in schizophrenia patients assessed before and following the first psychotic episode. Schizophr Res. 2003; 65:87-94. [PubMed: 14630301]

86. Seidman LJ, Faraone SV, Goldstein JM, Kremen WS, Horton NJ, Makris N, Toomey R, Kennedy $\mathrm{D}$, Caviness VS, Tsuang MT. Left hippocampal volume as a vulnerability indicator for schizophrenia: A magnetic resonance imaging morphometric study of non-psychotic first degree relatives. Arch Gen Psychiatry. 2002; 59:839-849. [PubMed: 12215084]

87. Seidman LJ, Thermenos HW, Poldrack RA, Peace NK, Koch JK, Faraone SV, Tsuang MT. Altered brain activation in dorsolateral prefrontal cortex in adolescents and young adults at genetic risk for schizophrenia: An fMRI study of working memory. Schizophr Res. 2006; 85:58-72. [PubMed: 16632333]

88. Klosterkotter J, Hellmich M, Steinmeyer EM, Schultze-Lutter F. Diagnosing schizophrenia in the initial prodromal phase. Arch Gen Psychiatry. 2001; 58:158-164. [PubMed: 11177117]

\section{NAPLS Group}

Jean Addington, Diane Kirsopp, Ivana Furimsky, Irvin Epstein, \& Robert Zipursky (Toronto, Canada); Donald Addington \& Anna Gresko (Calgary, Canada); Kristin Cadenhead, Kathleen Shafer, Iliana Marks, Katherine Seeber, Nasra Harou, \& Karin Kristensen (UCSD); Tyrone Cannon, Jennifer Johnson, Carrie Bearden, Mary O'Brien, Melita Daley, Tara Niendam \& Jamie Zinberg (UCLA); Barbara Cornblatt, Christopher Smith, Andrea Auther, Pradeep Nagachandran \& Joshua Biener (Zucker Hillside Hospital); Diane Perkins, Johanna Boobas, Jennifer Nieri, \& Karen Graham (UNC); Larry Seidman, Ming Tsuang, Anthony Giuliano, Eric Meyer, \& Lynda Tucker (Harvard University); Elaine Walker \& Shivali Dhruv (Emory University); Scott Woods, Thomas McGlashan, Tandy Miller, Roy Money \& Philip Markovich (Yale University); Robert Heinssen (National Institute of Mental Health).

\section{Funding Sources}

Grant numbers (in parentheses) are given for sources to the principal investigators that specifically supported this work. Dr. Seidman reports that he currently or in the past 12 months has received investigator-initiated research funding support from multiple not-forprofit entities including the National Institute for Mental Health (R18 MH 43518, U01 MH081928, P50 MH080272), the National Institute of Aging, the Commonwealth of Massachusetts Department of Mental Health, the National Association for Research in Schizophrenia and Depression (NARSAD), and the Sidney R. Baer Foundation. He has not received funding from for-profit entities in the past 12 months. In the past he has received unrestricted educational support from Janssen Pharmaceuticals and has served as a consultant for Shire. Dr. Giuliano reports that he currently or in the past 12 months has received investigator-initiated research funding support from multiple not-for-profit entities including the National Institute of Mental Health and the National Association for Research in Schizophrenia and Depression (NARSAD). Dr. Meyer reports that he currently or in the past 12 months has received investigator-initiated research funding support from the U.S. Department of Veterans Affairs. Dr. Addington reports that she currently or in the past 12 months has received investigator-initiated research funding support from multiple not-forprofit entities including the National Institute for Mental Health (U01 MH066134), Ontario Mental Health Foundation and the Schizophrenia Society of Ontario. Dr. Addington reports that she has served as a consultant for Pfizer, AstraZeneca and Janssen Pharmaceuticals. Dr. Cadenhead reports that she currently or in the past 12 months has received investigatorinitiated research funding support from the National Institute for Mental Health (R01 MH60720 and K24 MH76191). Dr. Cannon reports that he currently or in the past 12 months has received investigator-initiated research funding support from multiple not-for- 
profit entities including the National Institute for Mental Health (R01 MH65079), the National Alliance for Research on Schizophrenia and Depression, and the Staglin Music Festival for Mental Health. Dr Cannon reports that he has served as a consultant for Janssen Pharmaceuticals and Eli Lilly. Dr. McGlashan reports that he currently or in the past 12 months he has received investigator-initiated research funding support from the National Institute of Mental Health (K05MH01654), the Personality Disorder Research Foundation, and Eli Lilly Company. Dr. McGlashan reports that he has served as a consultant for Lilly, Pfizer, Solvay/Wyeth, and Roche pharmaceuticals. In the past 12 months Dr. Perkins (U01 MH066069 and P50 MH064065) reports having received research funding from Janssen Pharmaceutica Products and Dainippon. In the past, Dr. Perkins reports having received research funding from AstraZeneca Pharmaceuticals LP, Bristol-Myers Squibb, Otsuka Pharmaceutical Co. Ltd, Eli Lilly and Co., Janssen Pharmaceutica Products, and Pfizer Inc.; and consulting and educational fees from AstraZeneca Pharmaceuticals LP, Bristol-Myers Squibb, Eli Lilly and Co., Janssen Pharmaceuticals, GlaxoSmithKline, Forest Labs, Pfizer Inc and Shire. Dr. Tsuang reports that he currently or in the past 12 months has received investigator-initiated research funding support from multiple not-for-profit entities including the National Institute for Mental Health (R18 MH43518), and reports that he has received research grants from Janssen. Dr. Walker reports that she currently or in the past 12 months has received investigator-initiated research funding support from not-for-profit entities including the National Institute for Mental Health RO1MH RO1MH062066 and 5 U01 MH081988, and the National Alliance for Research on Schizophrenia and Depression. She has not received funding from for-profit entities. Dr. Woods reports that he currently or in the past 12 months has received investigator-initiated research funding support from multiple not-for-profit entities including the National Institute for Mental Health (U01 MH74356, U01 MH082022, R41 MH083436) and the Donaghue, Stanley, and NARSAD foundations. In addition, he has received investigator-initiated research funding support from multiple for-profit entities including UCB Pharma, and Bristol-Myers Squibb and has consulted to Otsuka and Schering-Plough. Dr. Woods reports that he has not served on speaker's bureaus. Dr. Bearden reports that she currently or in the past 12 months has received investigator-initiated research funding support from the National Institute for Mental Health. She has not received funding from for-profit entities in the past 12 months. Dr. Christensen reports that he currently or in the past 12 months has received investigatorinitiated research funding support from multiple not-for-profit entities including the Canadian Institutes of Health Research, Ontario Neurotrauma Foundation, and the Ontario Mental Health Foundation. He has not received funding from for-profit entities in the past 12 months. In the past he has received research support from Eli Lily and has served as a consultant for Janseen Pharmaceuticals. Dr. Hawkins reports that he currently or in the past 12 months has received funding support from the National Institute of Mental Health, the Alzheimer's Disease Association, and the Department of Mental Health and Addiction Services of the State of Connecticut. Dr. Heaton reports that he currently or in the past 12 months has received investigator-initiated funding from the National Institute of Mental Health, the National Institute of Drug Abuse, and the National Institute of Neurological Disorders and Stroke. Dr. Keefe reports that he currently or in the past 12 months has received investigator-initiated research funding support from the National Institute of Mental Health and the Singapore National Medical Research Council, and an unrestricted educational grant from Astra-Zeneca. He currently or in the past 12 months has received honoraria or served as a consultant or advisory board member for Abbott, Astra-Zeneca, BiolineRx, Bristol Myers Squibb, Cephalon, Dainippon Sumitomo Pharma, Eli Lilly, Johnson \& Johnson, Lundbeck, Memory Pharmaceuticals, Merck, Neurosearch, Orion, Orexigen, Otsuka, Pfizer, Roche, Sanofi/Aventis, Shire, Targacept, Wyeth, and Xenoport. In the past, he has received honoraria or served as a consultant or advisory board member for Acadia, Cortex, Cyberonics, Forest, Gabriel, GlaxoSmithKline, Repligen, Saegis, SheringPlough, and has received research funding from Astra-Zeneca, Eli Lilly, Janssen, and Pfizer. 
Dr. Keefe receives royalties from the Brief Assessment of Cognition in Schizophrenia (BACS) testing battery and the MATRICS Battery (BACS Symbol Coding). Dr. Heinssen is an employee of the non-profit National Institutes of Health. He reports having no financial relationships with for-profit entities. Dr. Cornblatt reports that she currently or in the past 12 months has received investigator-initiated research funding support from not-for-profit entities including the National Institute for Mental Health R01 MH061523 and the Stanley Medical Research Institute. She has also served as a consultant for Lilly, Bristol-Meyers Squibb and Janssen Pharmaceuticals and has received unrestricted educational grants from Janssen. 


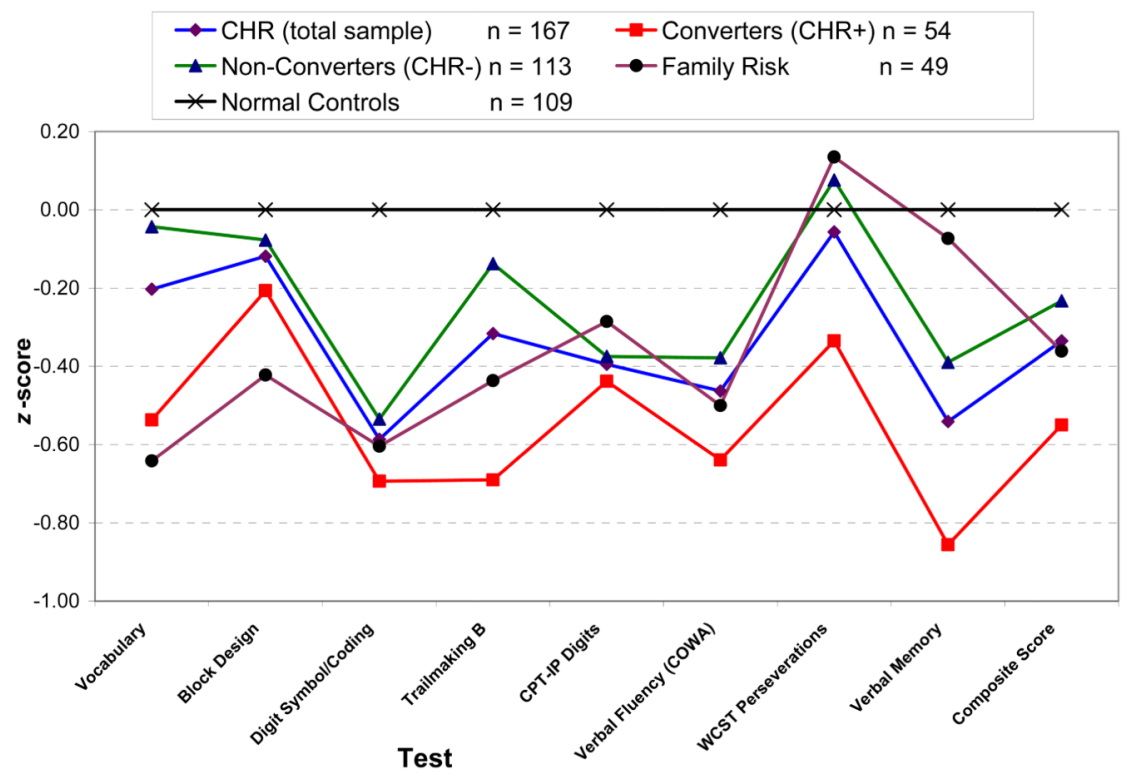

Figure 1.

Neuropsychological Profiles of CHR (Total Sample), CHR Converters, CHR NonConverters, and FHR Groups Standardized Against the Normal Control Group from the "Multivariate" Sample 


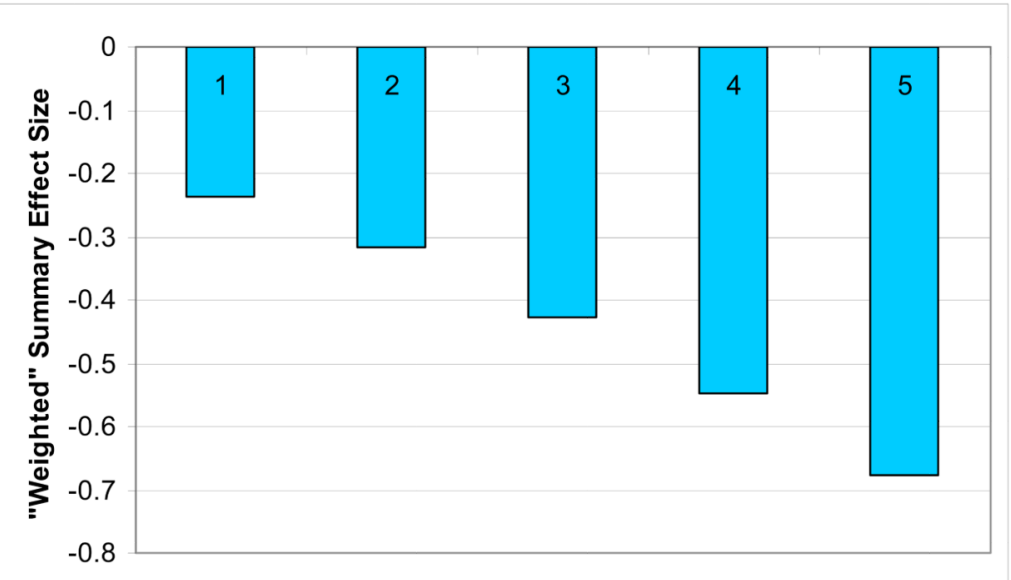

Figure 2.

Effect Sizes (ES) reflecting comparisons of different High Risk groups with normal controls. ESs (Cohen's $d$ ) are averaged within group in the "Univariate" sample after weighting for sample size across the 8 neuropsychological test variables. Data suggests a dose response impact of both conversion and family history of psychosis. Comparisons are as follows (average number of subjects per test per group in parenthesis: NC ( $\mathrm{n}=144)$ : 1) CHR NonConverters ( $\mathrm{n}=155)$; 2) CHR (total sample [n=242]); 3) FHR ( $\mathrm{n}=45)$; 4) CHR Converters $(\mathrm{n}=62) ; 5)$ CHR Converters/FH+ $(\mathrm{n}=13)$. 


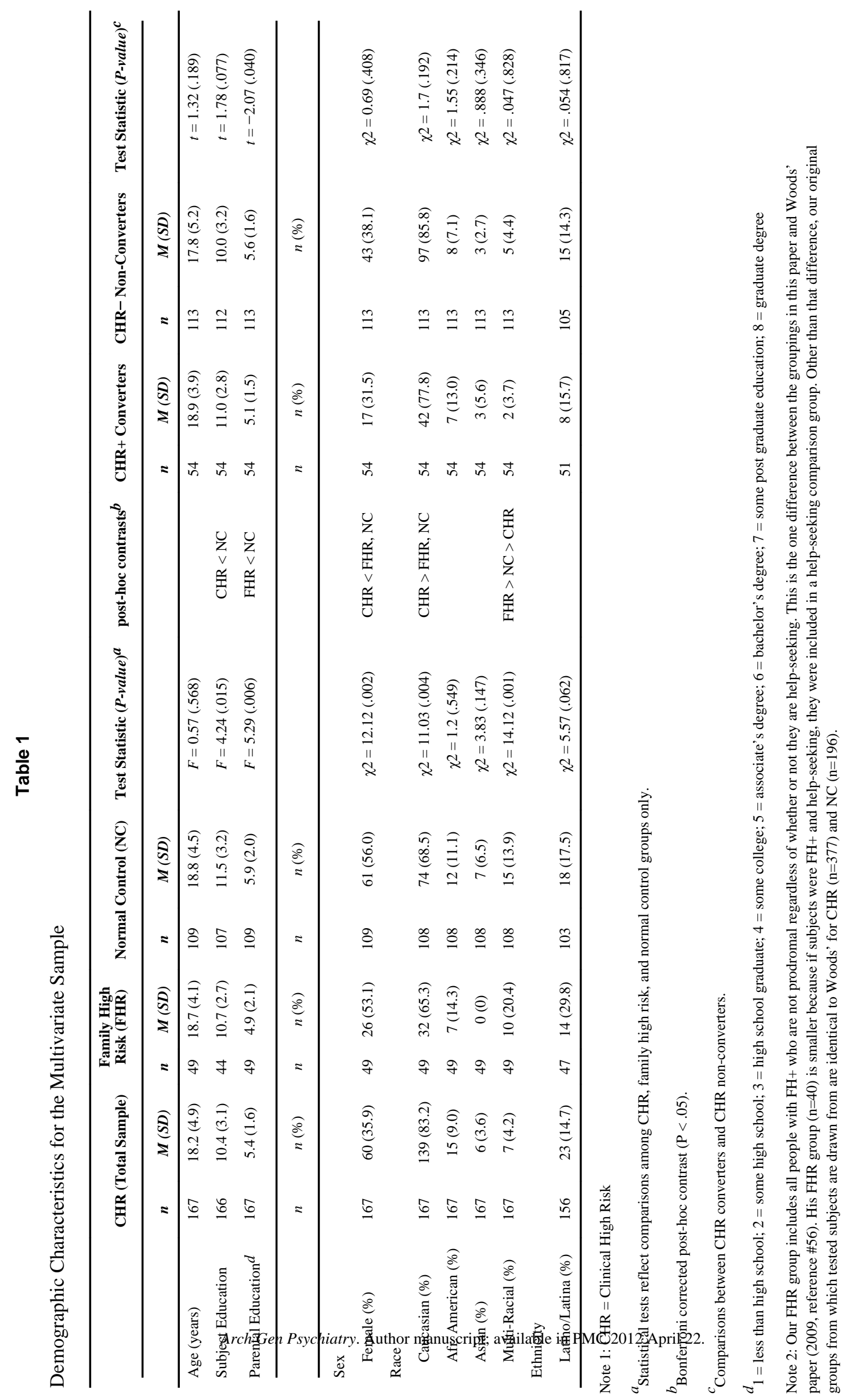




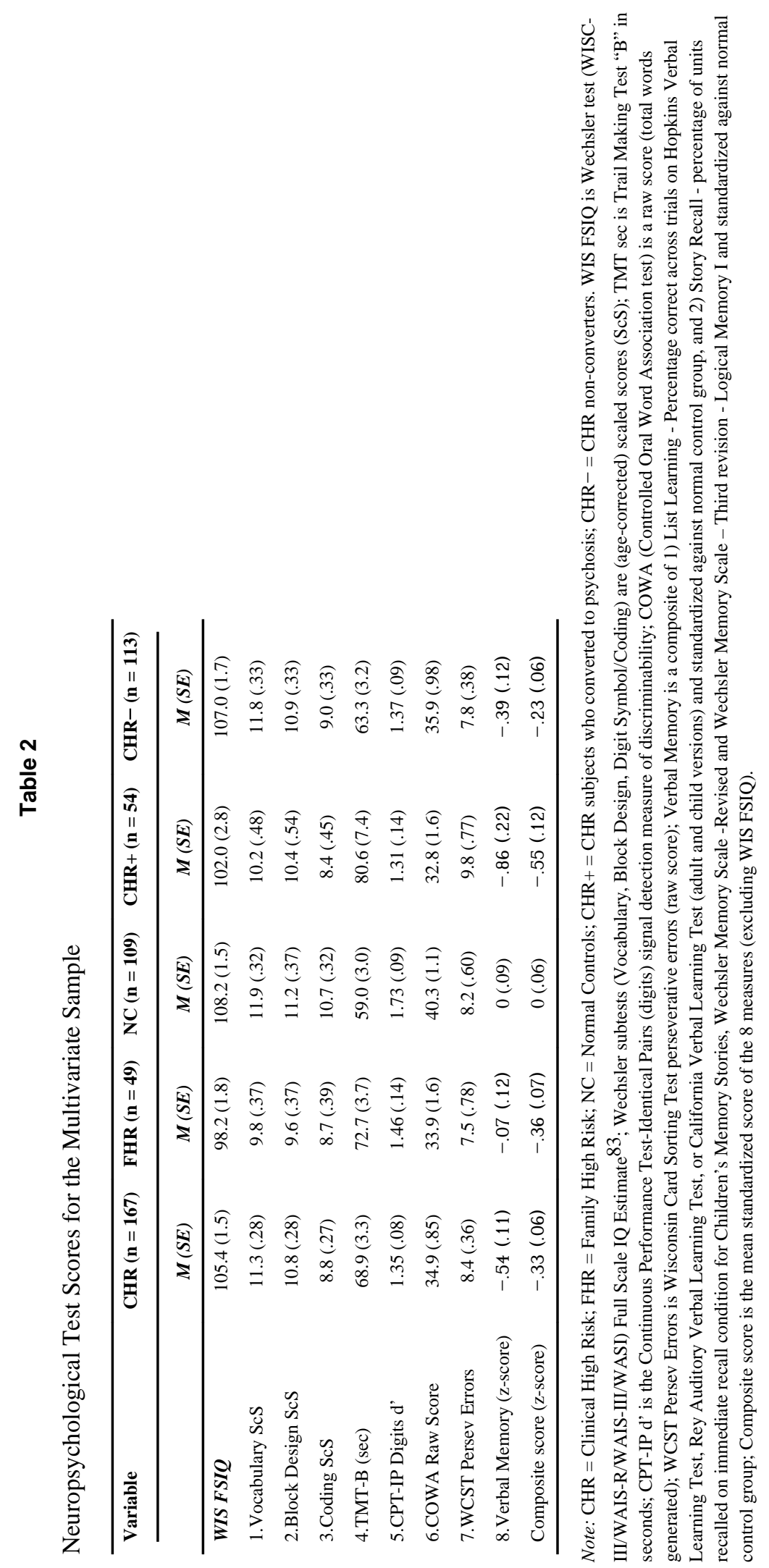




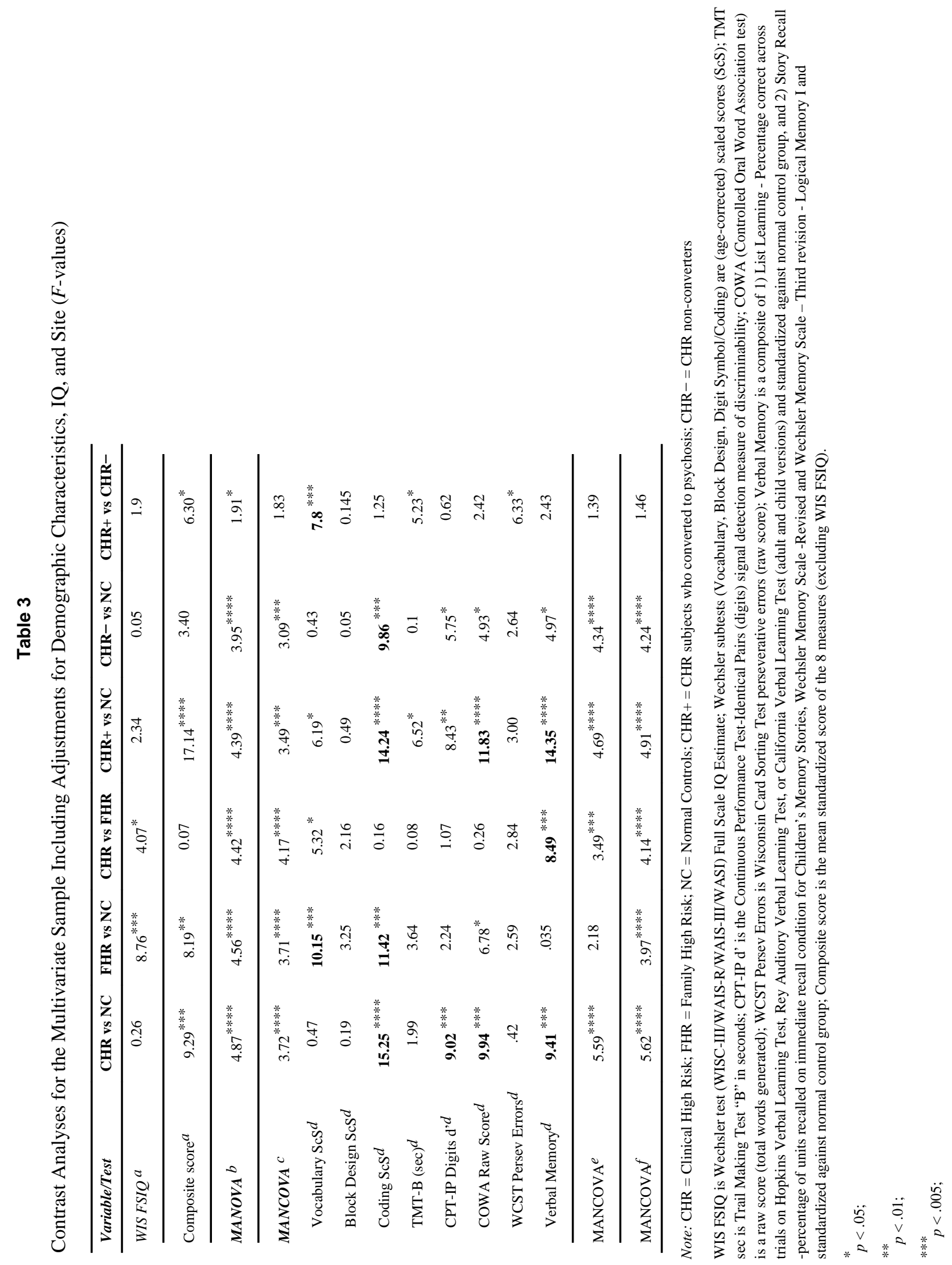




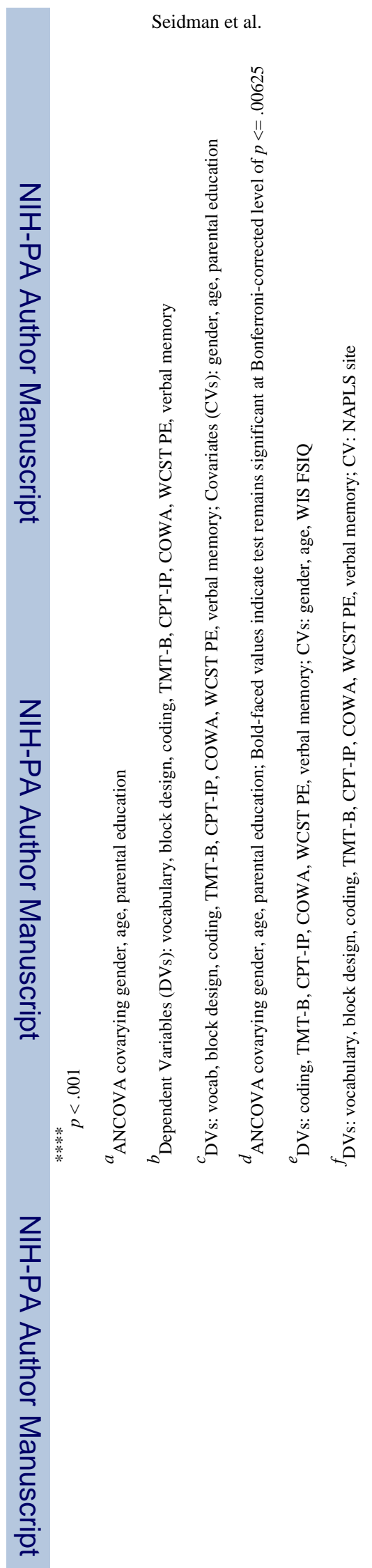

Page 23

Arch Gen Psychiatry. Author manuscript; available in PMC 2012 April 22. 


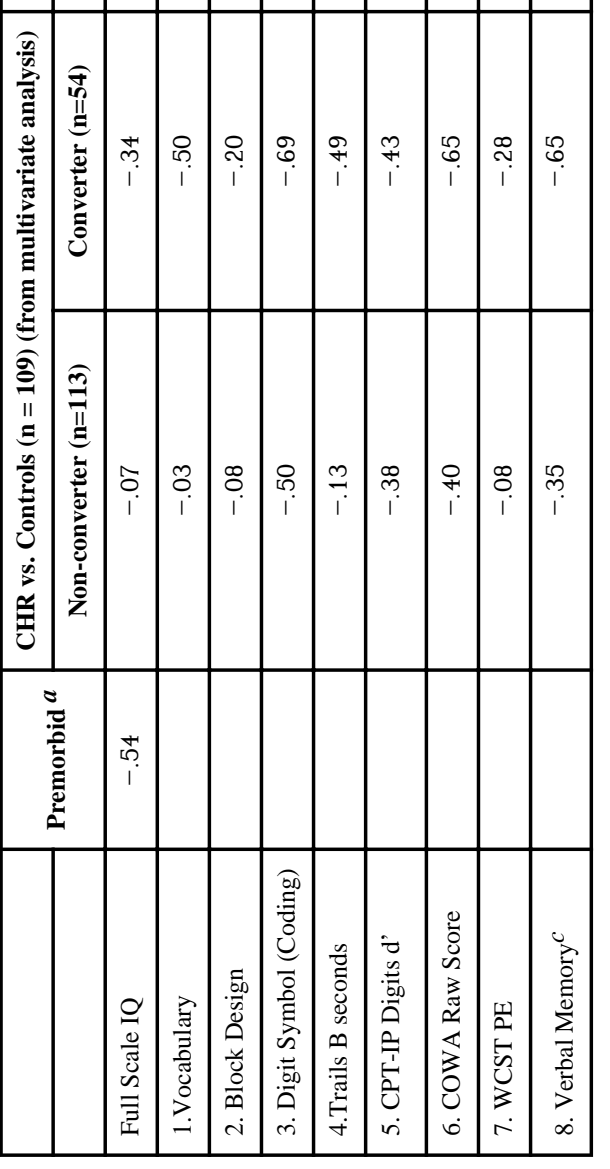

